\title{
Representações de adoecimento e cura de pacientes do Centro de Dependência Química do Hospital Central da Marinha
}

\author{
Representations on patient illness and cure at the chemical dependency center \\ of the Central Navy Hospital
}

Elizabeth Espindola Halpern ${ }^{1}$

Ligia Maria Costa Leite ${ }^{1}$

\footnotetext{
${ }^{1}$ Instituto de Psiquiatria, Universidade Federal do Rio de Janeiro. Av. Venceslau Brás $71 /$ fundos, Botafogo. 22.290-140 Rio de Janeiro RJ. espindolahalpern@yahoo.com.br
}

\begin{abstract}
This article presents one of the segments of ethnographic research which was conducted over a two-year period, by means of participant observation, at the Chemical Dependency Center of the Brazilian Navy. Patients of 2 treatment groups were observed during 24 sessions of group therapy. Among the 22 existing patients of the two groups, 13 patients were randomly selected for individual interviews. Their illness and healing representations related to mental and behavioral disorders caused by drugs were examined, and also the influence of the work environment on patient involvement with drugs was investigated. Results show that patients believe that they are responsible for their illness and for their alcoholic sobriety and they also believe they will never be cured. Furthermore, they do not usually accept the on-going medical discourse or the Alcoholics Anonymous belief that they are recovering alcoholics; they build their own views about their diagnoses, prognoses, and treatments. There are cultural traits particular to the naval life that indicate that the categories analyzed are mainly social, and that certain work-related conditions lead to the emergence of alcoholism in many patients, despite the fact that drugs are commonly tackled from the administrative perspective.
\end{abstract}

Key words Alcoholism, Military, Occupational health
Resumo Este artigo apresenta um dos segmentos de uma pesquisa etnográfica feita ao longo de dois anos, por meio da observação participante, no Centro de Dependência Química (CEDEQ) da Marinha do Brasil (MB). Pacientes de dois grupos terapêuticos foram observados durante 24 sessões de grupoterapia. Entrevistas individuais após as sessões ocorreram com 13 pacientes escolhidos aleatoriamente dentre os 22 militares dos dois grupos. Objetivou-se examinar suas representações de adoecimento e cura relacionadas aos seus diagnósticos de transtorno mental e comportamental devido ao uso de drogas, além de investigar a influência do ambiente de trabalho no envolvimento dos pacientes com drogas, em particular com o álcool. Resultados apontam que os pacientes passam a crer que são os principais responsáveis pelo seu adoecimento e alcance da sobriedade, e que nunca serão curados. Todavia, eles nem sempre aderem ao discurso médico vigente e à visão dos Alcoólicos Anônimos de que são doentes alcoólicos em recuperação, construindo percepções sobre seus diagnósticos, prognósticos e tratamentos. Concluiu-se que traços culturais peculiares à vida naval indicam que as categorias analisadas são, sobretudo, sociais e que certas condições laborativas colaboram para a emergência do alcoolismo de muitos pacientes, apesar do uso de drogas geralmente ser abordado pelo viés administrativo.

Palavras-chave Alcoolismo, Militares, Saúde do trabalhador, Condições de trabalho 


\section{Introdução}

O Centro de Dependência Química (CEDEQ) da Marinha do Brasil (MB) é um ambulatório de tratamento aos dependentes químicos pioneiro nas Forças Armadas brasileiras. Apesar da implantação de outras abordagens na $\mathrm{MB}$ relacionadas à prevenção e à desintoxicação, ainda não foram realizados levantamentos para avaliar o impacto dessas iniciativas no ambiente laboral. Logo, esta pesquisa é um estudo inaugural nesta seara.

Esta investigação examina como os pacientes do CEDEQ constroem suas representações de adoecimento e cura, a despeito de sua estrutura encontrar-se imersa na racionalidade médica contemporânea ocidental ${ }^{1,2}$. Apesar de prevalecer uma visão na sociedade moderna da dependência química como transtorno mental, importa conhecer quais vêm a ser as percepções desses sujeitos, dando relevo às experiências subjetivas relativas aos seus "processos mórbidos". Interessa analisar como eles aderem ou não ao discurso vigente que modela as categorias saúde e doença por meio de um conjunto de atividades (práxis), arte de curar (tekné) e conhecimentos (gnose, episteme $)^{3}$. Subjacente a esta investigação se assenta a crença de que essas categorias, mais do que serem objetos exclusivos da razão médica moderna, são sociais ${ }^{1}$. Enfim, deseja-se destacar quais seriam os seus pontos de vista sobre seus diagnósticos, prognósticos e tratamentos, considerando-se que eles fazem parte de um processo de enquadramento que não é unicamente lógico e racional ou baseado em operações conceituais, segundo preconiza a ciência moderna ${ }^{4}$.

\section{CEDEQ}

O CEDEQ, inaugurado em 1997, tem um programa de tratamento com cinco etapas: Grupo Motivacional, Fases I, II e III e Grupo de Consolidação, cada qual com duração mínima de quatro meses, dependendo da evolução individual, visando o alcance da abstinência e s reformulações na forma de agir e pensar. As fases possuem um número mínimo de sessões e atividades, além de metas a serem atingidas. A condução da grupoterapia se utiliza tanto do enfoque psicodinâmico, de base psicanalítica, quanto de estratégias comportamentais, com a discussão sobre temas atinentes à dependência química, com a leitura da literatura dos Alcoólicos Anônimos (AA) e com exibição e debate de filmes.

Os pacientes são acompanhados pela Psiqui- atria e pelo Serviço Social. O tratamento, embasado nos 12 Passos e 12 Tradições dos AA, visa auxiliá-los a evitar o "primeiro gole" e a manter a sobriedade. Privilegia-se o atendimento em grupo por se acreditar que a ajuda mútua facilite a superação da adicção $0^{5}$.

Militares com idade superior a 18 anos ingressam no CEDEQ voluntariamente, por ordem do Comando ou judicial e/ou mediante encaminhamento de profissional da saúde. Considerando que o tratamento ocorre no horário de trabalho, a autorização para comparecer às consultas exige o cumprimento das formalidades administrativas que são peculiares à administração naval. A Licença para Tratamento de Saúde (LTS), que é um afastamento temporário, pode ser concedida após a avaliação da Junta de Saúde. Em geral, os pacientes que fazem uso de medicação psiquiátrica costumam ter restrições laborativas, deixando de participar de formaturas, manobras, embarques e de dar serviço noturno armado.

A totalidade dos pacientes faz parte da carreira das Praças, uma maioria numérica da $\mathrm{MB}$ que está na base da pirâmide hierárquica, incumbidos de realizarem tarefas de manutenção e operação de equipamentos, bem como de conservação de compartimentos de suas unidades militares conforme suas especialidades, segundo dispõe o Estatuto dos Militares ${ }^{6}$. Os Oficiais raramente frequentam o CEDEQ, optando por consultas particulares e medicamentosas.

\section{Método}

Uma pesquisa qualitativa etnográfica, por meio de observação participante, vem sendo realizada de forma sistematizada no CEDEQ há cerca de dois anos para conhecer o seu funcionamento e as propostas terapêuticas ${ }^{7}$. A pesquisa foi deferida pelo Comitê de Ética em Pesquisa da MB. Os pacientes assinaram o Termo de Consentimento Livre e Esclarecido concordando que as entrevistas fossem gravadas em MP3. Pseudônimos foram dados para preservar a identidade dos participantes.

O enfoque desse artigo apresenta uma das vertentes da pesquisa que se desenvolveu em dois grupos terapêuticos, em 2010, durante 24 sessões de grupoterapia. Após as sessões foram realizadas entrevistas individuais e semidirigidas (open-ended) para identificar o perfil demográfico e suas representações de adoecimento e cura. Para tal, foram escolhidos aleatoriamente 13 pa- 
cientes para serem entrevistados dentre os 22 militares dos dois grupos Motivacionais, que correspondem à primeira fase do tratamento.

A utilização de entrevistas semiestruturadas é uma estratégia que auxilia o entrevistado a contar sua história do seu jeito, em consonância com a perspectiva construtivista por meio da qual o entrevistador e entrevistados encontram-se envolvidos na construção de significados ${ }^{8}$. Logo, o número de entrevistas e sua duração não foram pré-determinados, permitindo que o processo de interação ditasse sua profundidade, duração, rumo e intensidade.

A autora principal, que foi a pesquisadora de campo, teve um estatuto duplo por ser, ao mesmo tempo, integrante da equipe de profissionais do CEDEQ. Isto permitiu incorporar à pesquisa os conhecimentos oriundos de mais de seis anos de prática neste espaço, incluindo sua participação nos grupos terapêuticos, na organização de cursos de dependência química e na apresentação de palestras em diversas unidades militares da MB. O seu posicionamento facilitou a autorização da pesquisa por desfrutar de uma oportunidade privilegiada de coletar dados. Ao construir uma perspectiva como alguém de "dentro", foi possível capturar as circunstâncias do cotidiano da vida dos sujeitos ${ }^{9}$ que ilustram uma dinâmica similar à de outros militares.

O processo de coleta e de interpretação dos dados foi feito de forma interativa e não sequencial $^{10}$, de modo retrospectivo e circular ${ }^{11}$, acompanhando a evolução do raciocínio da autora principal.

\section{Representações de adoecimento e cura}

Embora a visão hegemônica corrente sobre a dependência química seja fruto do modelo biomédico que a vê como um desvio de uma função normal ${ }^{12}$, por meio dos relatos dos pacientes foi possível ampliar essa visão, compreendendo-a como um traço da cultura ${ }^{13}$. A adicção seria um fenômeno gerido individual e coletivamente ${ }^{14}$ envolvendo eventos imersos no estilo de vida urbano $^{15}$ que são característicos das sociedades urbanas complexas.

\section{Resultados}

A visão sociocultural da toxicomania ${ }^{16}$ a respeito da drogadicção revelou-se um aspecto central neste estudo, conferindo uma maior inteligibilidade às representações de adoecimento e cura enunciadas pelos pacientes nas entrevistas, ajudando a descolar suas falas do discurso médico hegemônico.

As entrevistas revelaram como os pacientes constroem definições sobre si mesmos como dependentes químicos, aspecto que se esclarece e consolida ao longo do processo terapêutico. Inclusive, alguns se encontram em franco processo de assimilação da ideia de serem adictos. Alguns relatos sobre o juízo que têm a respeito de seus problemas de saúde serão apresentados a seguir:

Geraldo: O CEDEQ foi um local onde tive realmente contato com a minha doença. Saber aquilo o que me levou a ter mais conhecimento de mim mesmo, me aprofundar na pessoa que eu sou. Muitas pessoas dizem que é 'balela'. Pra mim foi um local que abriu meus olhos, abriu minha mente pra minha doença. Até então achava que não era doente, que não tinha problema nenhum. Aprendi que era uma doença através das literaturas, das terapeutas aí, do que era passado.

Pedro: Depois da internação de um mês, não me falaram diretamente, só me indicaram pro CEDEQ. Não me falaram muito claramente. Só perceberam que meu fígado estava TGO, TGP. Tava alto! Ficou claro pra você o porquê dessa indicação? A dependência, né?! Vagner afirma: Sou alcoolista! Não tenho controle perante a bebida. Dizem que todas a pessoas que não têm controle perante a bebida são alcoólatras.

Embora os pacientes se considerem dependentes químicos, suas percepções são construídas nos espaços médicos, inclusive no próprio CEDEQ ao longo da terapia de grupo, onde se prega que a adicção é uma doença incurável. A ideia de não ter controle sobre a droga é desenvolvida no processo terapêutico e os pacientes assimilam esse tipo de leitura a respeito de suas experiências com as substâncias. Mesmo que predominem frases como: "não tenho controle perante a bebida", apreendidas nas salas de AA e NA e nas sessões terapêuticas do CEDEQ, diferenças de ethos e de visão de mundo podem ser constatadas, o que se singulariza no uso das drogas. Para a sua elucidação, cabe considerar o papel da cultura: "A noção de cultura valoriza a rede de significados, a construção social da realidade, a identificação do arbitrário e a percepção das diferenças de visão de mundo e estilo de vida" ${ }^{17}$.

Ser alcoólatra, em particular, significa ser dominado pelo álcool ${ }^{18}$ como resultado de uma necessidade física que se impõe à própria vontade do indivíduo. "A teoria da doença concebe o alcoolismo como uma 'doença inata', enraizada no organismo do alcoólico, que constrange a 
vontade do indivíduo, impedindo-o de agir de modo responsável”"19.

Embora exista um esforço para se ter uma explicação racional do problema de saúde que, em última análise, parece reproduzir o discurso hegemônico biomédico, muitos pacientes recitam falas, aparentemente decoradas e aprovadas pelo grupo, sugestivas de recuperação. Paulatinamente, os pacientes assimilam a ideia de que são "portadores" de uma doença: alcoolismo ou dependência química, desde o momento em que são avaliados por um profissional da saúde. É como se a própria experiência individual com o uso de substâncias psicoativas ganhasse contornos e fronteiras permitindo que a dependência, como doença, ganhasse existência (enactment) por meio de técnicas que tornam objetos visíveis, audíveis, tangíveis e conhecíveis. Conforme propõe o perspectivalismo, o sujeito e sua doença não pré-existem à experiência etnográfica, revelam-se de modo sincrônico a partir das relações que têm ${ }^{20}$. Porém, ao serem convidados a explicar melhor como adoeceram, suas respostas parecem levantar dúvidas à certeza anterior, como se pode constatar pelos próximos relatos:

Você se considera alcoólatra? Não. Tenho dúvidas, tenho dúvidas. Às vezes eu bebo no final de semana, só. A bordo pode servir bebida, mas eu bebo se eu quiser. Eu não fico com aquela fissura de beber. Quando tô trabalhando eu não sinto aquela necessidade. Já senti!(João). Hélio: Eu nunca acreditei que usuário de droga fosse um doente, pra mim era safadeza. Me diagnosticaram aqui, no CEDEQ. Geraldo: É doença porque foi provado, todos dizem que é. Tanto é que tá na Organização Mundial de Saúde como doença. Antigamente era sem vergonhice. Qual é a tua opinião? Sou meio leigo, talvez alguém mais inteligente que eu achou que é isso aí. Pra mim é coisa espiritual.

Muitos são categóricos quando expressam o gosto pela substância como um fator determinante que pode explicar o alcoolismo: Eu era alcoólatra mesmo, eu gostava mesmo da bebida. Não tinha motivo. É gostar mesmo! Gostava da cerveja mesmo, gostava da Ypióca [cachaça] com limão (Pedro). Wando se pronuncia: Gosto de beber cerveja, gosto mesmo, bebo por gosto, sem nenhum motivo.

Por outro lado, a ideia de cura não parece estar associada à de doença orgânica ou genética como muitos pacientes consideram, pois a prescrição parece estar associada a uma terapia onde o remédio mais eficaz é o diálogo, a troca com outros pacientes, compartilhando experiências.

Hélio corrobora: Tem coisas que eu não acreditava. Essa coisa de psicologia eu achava meio boba. Mas eu acho que é por ali mesmo. Alguém pra conversar com você. Vê o caso de outra pessoa, vê que você não tá sozinho, com mais gente passando por isso.

Márcio: Acredito que tem jeito, né!? Qual é o jeito? Não sei... [fala baixinho]. Você tá na dúvida? Acho que falar, abrir, conversar, a vida sem aquele julgamento. Tá todo mundo no mesmo barco, vamos dizer assim. Aqui não tem aquele julgamento, você pode falar à vontade. Tem um trecho do poema de Shakespeare que fala: 'Falar alivia as dores emocionais'. Acho que é isso: falar alivia as dores emocionais!.

Você tem cura? Tenho, todos nós temos! Eu sei que o alcoolismo é uma doença, que não tem cura. E qual é o tratamento? Tem que frequentar muita sala de AA, ouvir as experiências. Inclusive as pessoas falam que é a derrota dos outros, você escutando as pessoas. Aquilo também te ajuda. Você não quer passar o que aquela pessoa já passou. Sempre tenho que tomar meu remedinho, que é as salas de recuperação (Vagner).

Apesar da grande maioria dos pacientes se considerar dependente químico, alcoólico ou doente, ainda que com alguma incerteza, ao longo das entrevistas eles tenderam a conferir um peso substantivo aos fatores externos para justificar a adicção. Isso pode ser atestado nas entrevistas, sobretudo no que se refere à influência do ambiente de trabalho no desencadeamento da dependência. Alguns destacam o stress relativo às condições laborativas:

Nós, Praças, somos simplesmente massa de obra, massa de trabalho! Geralmente, quando o navio chega no porto, tem aquele 'rasga'. Tem o quê? Rasga, quando o navio vai atracar, na véspera da atracação. É liberado cerveja, whisky (José).

Américo esclarece: Ah, não sei como posso falar pra Senhora [referindo-se à entrevistadora]. Só se ficar dentro do navio pra saber [risos]. Dá uma ideia? Ah, acontece muita coisa. Além do navio em si mesmo, do próprio proporcionar bebidas a bordo. A gente sai de porto em porto também. Há o estresse, sabe, interno também. Tem Comandante que, pô, acaba com você ao ponto de você querer encher a cara, vamos dizer assim. Fora que, vamos dizer assim, se fosse pegar um grupo de autoajuda pra colocar o pessoal dentro que tá precisando na Marinha, écapaz da Marinha toda tá dentro! Acho que tem gente que tá até pior que eu mesmo nessa situação. Embarquei num navio que, pô, praticamente tudo o que acontecia tinha bebida! Tudo isso é um incentivo!

Pedro descreve o hábito nas manobras: Levava a cachaça pras manobras, no meio do mato. 
Era aquela brincadeira! Não tem como tomar cerveja no meio do mato, a gente levava a cachaça. Leva o 'tubo' [cachaça em um galão] e o 'edredon líquido' [cachaça para aquecer]. João declara: $O$ sistema na Marinha, ou você bebe ou você é de alguma religião. Sempre bebemos, tanto a bordo, nas comemorações, aqueles aperitivos do 'rancho' [refeitório], no navio que eu servi também, quando faz a 'baldeação' [limpeza do navio]. Na baldeação era liberado! E era cachaça mesmo! Quando chegava no porto a galera queria mais é tirar aquela pressão toda! Então cheguei no ponto de explodir.

Manoel fala do stress na MB: A Marinha, ela estressa a pessoa. Trabalho, trabalho estressa! Dependendo do lugar que a gente estiver então! $\mathrm{Na}$ Marinha tudo é pra ontem! Tá na era da informática, mas na Marinha não acaba papel! Se acabar o papel, acaba a Marinha! Tem um monte de computador, mas a autoridade quer o papel.

Outros fatores relacionam-se às oportunidades de beber a bordo, que se encontram imiscuídas à execução das "fainas" (atividades) navais, pelo costume ou para atenuar o desgaste, o sentimento de opressão ou a fadiga:

Márcio reclama: Vamos botar assim: na Marinha, as pessoas saem muito, geralmente pra noitada. Porque quem tá casado pode dar desculpa que tá de serviço [com pernoite a bordo]. É um emprego meio atípico, né!? Na Marinha todo mundo sai muito, bebe muito, as pessoas tão sempre bebendo. É um jeito de desestressar também porque o sistema militar é um pouco maçante. Maçante? A rotina, tem manobra pra caramba. O cara vive a bordo!.

Geraldo expõe: Semana passada teve quatro eventos, comemoraram não sei o que lá, comida e bebida à vontade. Nas manobras, então, se não tiver, vai ter problema! Depois de um dia estressante, de trabalho, 'ralação', o cara quer dar aquela 'anestesiada'. Eu comecei a beber na Marinha! Entrei muito novo na Marinha, e aí, o que você aprendia: 'soco' [passeios à procura de aventuras amorosas], 'mulheril'. Na manobra tinha que ter a bambona de cachaça, vai tirando um gosto nos intervalos. Rodrigo confirma o uso a bordo nas atividades diárias: Toda a oficina tem sempre a bendita cachaça. Qualquer oficina, em qualquer quartel, sempre tem. Pode não ter numa oficina, mas na outra tem. Pelo menos no quartel onde eu tô, nas oficinas, sempre existiu Toda sexta-feira tem aquela caipirinha. Quantas vezes eu vi gente sair bêbado! Aî vem aquela pergunta: 'Bota caipirinha ou corta a caipirinha?' No dia que tem, nem almoçar eu posso!

A Marinha facilita o beber? Facilita, facilita. Muitas vezes nos coquetéis o pessoal usa o álcool, cerveja, às vezes caipirinha. No final de semana tem uma feijoada, caipirinha. Isso aí só vai aumentando. Tem bebida a bordo. Se eles podem, eu posso também! Essa é a mentalidade que mais aparece! Quem são eles? Os Oficiais (Tomé).

Embora a maneira desses pacientes consumirem bebidas alcoólicas possa ser enquadrada segundo os critérios dispostos nos manuais diagnósticos oficiais, ela geralmente é identificada no trabalho quando os padrões de consumo trazem prejuízos a bordo. Portanto, é no embate diário que o alcoolismo se constitui. As entrevistas revelaram que quando as suas formas de beber passaram a trazer problemas no trabalho, a condição mórbida se definiu e se tornou visível: Foi assim que aprendi na Marinha: quando você começa a errar muito, quando você não sabe gerenciar e aí traz problemas administrativos. Quando você tá bebendo socialmente [faz sinal de aspas], tá tudo bem. Não é permitido pelo RDM [Regulamento Disciplinar para a Marinha]. Quando tem uma festa, era pra ter refrigerante! Os Comandantes, Almirantes mandam vir bebida. O mau exemplo vem de cima. Não é autorizada bebida, mas tem OM [Organização Militar] que permite. Não tem regra geral, é de Comando pra Comando (Geraldo).

Manoel conta o que um superior hierárquico lhe disse: É, eu vou te apertar [exigir], mas daqui a pouquinho vai ficar tudo tranquilo, entendeu? Vai beber seu choppinho, sua cerveja. Ao exigir maior produtividade do subordinado, em troca assegura que a bebida amenizará o desgaste, como uma forma de recompensa: Manoel conclui: Aí o cara abusa e fica taxado de cachaceiro, alcoólatra.

Parece haver uma relação da origem da adicção com a ideia de "contágio", como se fosse uma "doença de família" ${ }^{\text {. }}$. Ao falar sobre origem da sua adicção, João opina: Acho que é esta ansiedade que eu tenho, eu tenho o sistema nervoso, assim muito nervoso, né?! Nervoso de que? Acho que é patológico mesmo! Acho que é uma doença, uma doença do sistema nervoso. Acho que vem da infância. Meu pai bebia muito! Pedro esclarece: Tem alguma coisa de genética, eu acho que tem. Meio genética, meio espiritual. Manoel diz: Acho que é psicológica. Meu pai era alcoólatra, inclusive morreu de cirrose. Tem uma parte genética, outra por problema dentro de casa, sabe?! É uma série de fatores. Vagner fala: Dizem, como se diz, que é genético, que vem dos pais, meu pai também era alcoólico. Eu sempre dizia que não queria ser que nem meu pai. Acabou que eu fiquei do mesmo jeito!

As condições de trabalho da vida naval são apontadas como corresponsáveis pela busca por 
substâncias psicoativas, sobretudo o álcoo ${ }^{17}$, como Vagner relata: Você passar o que você passa na Marinha, não é mole não! A Marinha deixa você muito longe do convívio familiar, ela te dá o emprego e tira as coisas que você conquista: a família vive longe, aí você cai em depressão, você acha que as coisas tão perdidas. Algumas pessoas conseguem superar, outras não! Porque pra você é fácil se adaptar ao sistema! E a sua família que não tá dentro do sistema?

$\mathrm{Na}$ Marinha se o cara bebe, a tendência dele é beber mais. Qual navio que não libera cachaça direto? Todos eles! Todo navio libera! Igual foi no ano de noventa e quatro, eu passava uma semana em casa, um mês fora, a Marinha sugando a gente de todo o jeito. Toda a viagem nossa tinha uma cota de cachaça pra todo mundo bebendo, pra aguentar o psicológico totalmente abatido! A gente praticamente nem via as crianças em casa. Chegava em casa hoje, daqui a dois dias tava 'suspendendo' [saindo em viagem de navio] de novo! (Rodrigo).

Outro aspecto laboral marcante refere-se às movimentações para outras localidades do país, afastando o militar da família e cultura. Vagner reclama: Você tá longe da sua família, você viver num Rio de Janeiro desse, que você mal conhece, aos 'troncos' e barrancos, aprender a se adaptar. $E$ escuro, você não sabe, você tá aprendendo a conhecer. A questão da distância da cidade natal pode ser avaliada na Figura 1 que apresenta a distribuição dos pacientes quanto à sua naturalidade, indicando que $46 \%$ dos entrevistados não são do Rio de Janeiro.

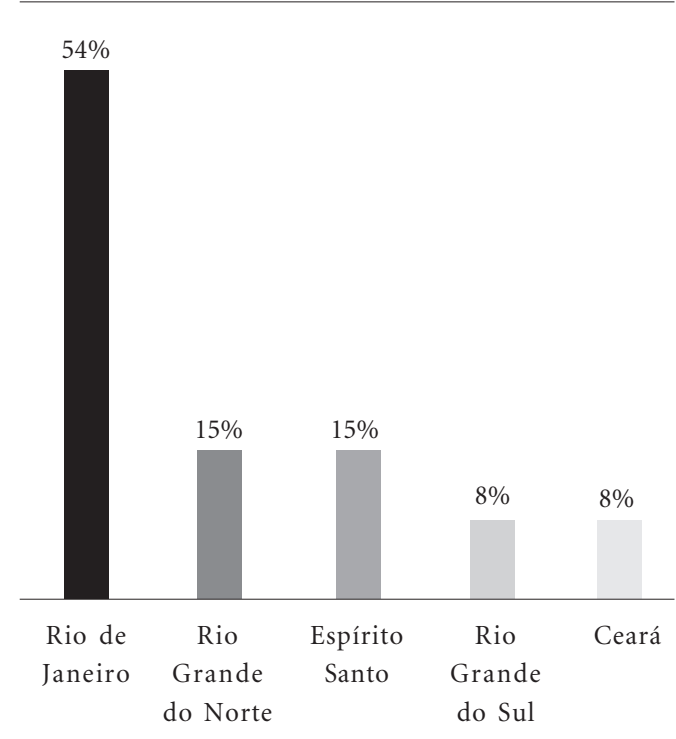

Figura 1. Naturalidade dos pacientes entrevistados
A solução institucional para o uso de drogas parece estar predominantemente associada aos recursos administrativos existentes, sobretudo ao RDM que prevê punições mediante a constatação da ocorrência de contravenções disciplinares. Wilson narra o diálogo que teve com o seu Encarregado: Às vezes eu pedia uma licença pra ele, e ele: 'Pra que você tá pedindo licença? Pra ir beber?' [Encarregado]. Às vezes eu precisava resolver um problema particular. Não conseguia [a licença]. Quando era no outro dia eu não vinha pra bordo. Aí, o que acontecia? Ele me prendia! Fui punido dentro dessa situação várias vezes. Você tinha que ter sido punido? Hã? Bom, eu acharia que não, né?! Precisava era de um tratamento, né?! Quando eu pedia um tratamento, o que é que acontecia? Eu viajava! [no navio]. Ele já te puniu alguma vez? Ih, já perdi até a conta! A solução que o Encarregado dá é colocar no Livro [Livro de Contravenção].

Constata-se que o CEDEQ, além de pouco conhecido na MB, é visto com reservas pelos próprios militares, o que dificulta a busca por auxílio. Pedro narra: Convidei um colega, que é um elemento muito perigoso, pra ir pro CEDEQ, mas ele falou uma coisa: 'Não quero ir pro CEDEQ não, já tentei uma vez. O CEDEQ é muito por ordem'. Aí falei pra ele: 'Não é muito por ordem, é Marinha, tem sempre um esqueminha'. Era muita regra demais pra cabeça dele.

Cabe esclarecer que a maioria dos entrevistados teria idade e tempo de serviço compatíveis com uma graduação superior, porém, ficaram estagnados em virtude da ocorrência de punições, geralmente relacionadas à adicção.

A Figura 2 assinala que a idade dos pacientes entrevistados é em média de 45 anos:

A Figura 3 apresenta os resultados referentes às graduações dos entrevistados, indicando que as de $3^{\circ}$ Sargentos (3० SG) e Cabos (CB) somam $61,53 \%$ dos casos. As graduações dispostas abaixo na Figura 3 encontram-se em ordem decrescente de antiguidade, segundo a hierarquia mili$\operatorname{tar}$ (da esquerda para a direita do gráfico), ou seja, de Suboficial (SO), a mais antiga, até Soldado Fuzileiro Naval (SD-FN), a mais moderna:

Não obstante a MB possuir um efetivo de 48.600 pessoas $^{21}$, o número de militares em tratamento nos últimos cinco anos manteve-se em torno de 50 pacientes/ano, o que corresponde a menos de $0,1 \%$ do efetivo naval. A maior parte permanece por mais de um ano em tratamento, cerca de $20 \%$ desistem e $8 \%$ recebem alta. O Quadro 1 exibe as drogas mais utilizadas pelos entrevistados, destacando-se que o álcool está presente em $100 \%$ dos casos. 
Pela análise dos dados estatísticos do CEDEQ dispostos na Figura 4, percebe-se que o número anual de atendimentos não tem aumentado, sobretudo se comparado ao número total de consultas/paciente/semestre realizadas desde 2001. Cabe esclarecer que os atendimentos/mês correspondem às sessões frequentadas.

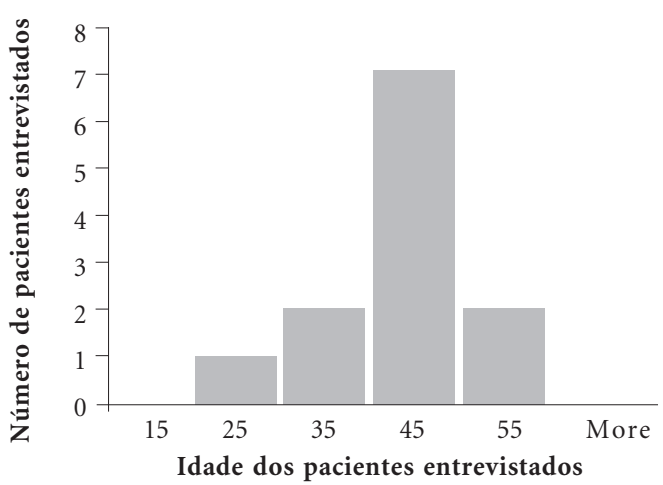

Figura 2. Idade dos pacientes entrevistados

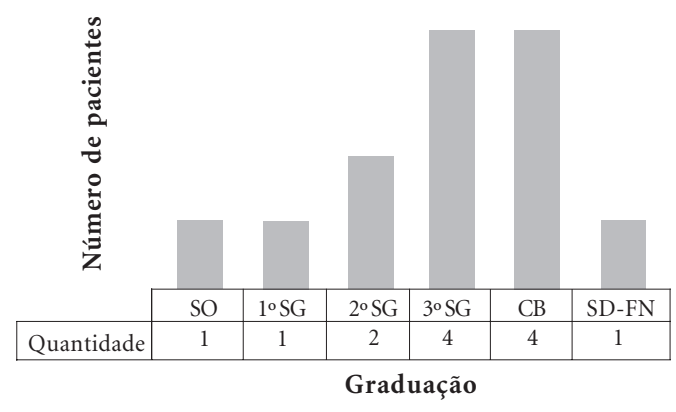

Figura 3. Graduação dos pacientes entrevistados

\section{Discussão}

O método de estudo de casos múltiplos foi uma estratégia de pesquisa particularmente útil por abarcar fenômenos sociais complexos ${ }^{9}$, como é o caso da dependência química. No meio naval brasileiro, espaço pouco visitado pelo olhar científico, o estudo de caso é uma ferramenta singular que permite uma investigação conservando as características mais significativas dos acontecimentos da vida real. Destaca-se que certos processos organizacionais e administrativos não são visíveis ao olhar externo, o que levou estudiosos a reconheceram a existência de resistências das instituições militares brasileiras a serem pesquisadas $^{22,23}$. A dificuldade de acesso se acentuou porque o consumo de bebidas na MB é um tema delicado. Não obstante, foi de suma relevância o fato de a pesquisadora principal trabalhar no CEDEQ, o que facilitou a realização da pesquisa. O estudo de casos múltiplos, por ser uma estratégia exploratória, inaugurou a investigação sobre o tema da dependência química na MB e permitiu um desenho descritivo do campo da pesquisa.

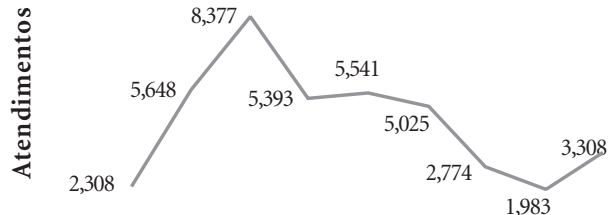

$\begin{array}{lllllllllll}2000 & 2001 & 2002 & 2003 & 2004 & 2005 & 2006 & 2007 & 2008 & 2009 & 2010\end{array}$

Ano

Figura 4. Número de atendimentos no CEDEQ

Quadro 1. Padrão de consumo de drogas dos pacientes entrevistados

\begin{tabular}{|l|c|c|}
\hline \multicolumn{1}{|c|}{ Drogas } & \multicolumn{1}{|c|}{$\begin{array}{c}\text { Drogas usadas pelos } \\
\text { entrevistados }\end{array}$} & \multicolumn{1}{c|}{$\begin{array}{c}\text { Drogas consideradas } \\
\text { como a “droga de escolha" }\end{array}$} \\
\hline Álcool & 13 pacientes $=100 \%$ & 11 pacientes $=84,61 \%$ \\
\hline Cocaína & 6 pacientes $=46,15 \%$ & 4 pacientes $=30,76 \%$ \\
\hline Maconha & 5 pacientes $=38,46 \%$ & - \\
\hline Outras (êxtase, crack, LSD, ácido) & 2 pacientes $=15,38 \%$ & - \\
\hline
\end{tabular}


O estatuto duplo da primeira autora, pessoal e profissional, exigiu seu permanente posicionamento de estranhamento e de reflexividade ${ }^{24}$. Esta postura representou um modo de olhar a partir de uma perspectiva que procura capturar a dimensão da experiência, assim como uma atitude que afeta a própria construção do relato. Weber ${ }^{25}$ postula que a própria seleção dos tópicos da pesquisa é guiada por valores, interesses pessoais e compromissos sociais do pesquisador. Esse aspecto foi um elemento de produção de conhecimento do campo de estudo e análise dos dados. Reconheceu-se que, embora seja um mundo social familiar, essa familiaridade é aparente, requerendo um trabalho de autoconsciência para proceder à objetivação dos elementos fundamentais ${ }^{26}$. Foi preciso ser capaz de transformar o familiar em exótico e o exótico em familiar ${ }^{27}$, enfrentando o desafio da proximidade ${ }^{28,29}$, sobretudo ao levar em conta a questão do comportamento padronizado e do desempenho de papéis da pesquisadora e dos pacientes ${ }^{30,31}$. O seu posicionamento permitiu mapear seu mundo. Barth ${ }^{32}$ ressalta que: “(...) cada pessoa está 'posicionada' em virtude de um padrão singular formado pela reunião, nessa pessoa, de partes de diversas correntes culturais, bem como em função de suas experiências particulares". Por pertencer a esse contexto e realizar essas observações durante um período longo ${ }^{33}$, algo que já se faz por força das contingências profissionais, foi possível desenvolver um conhecimento profundo, ainda que limitado por divisar certo ângulo de análise que se descortina pelo ponto de vista do observador e do observado. Verdade parcial que se extrai em meio a um emaranhado de discursos múltiplos, de mundos distintos e simultâneos, atravessados por correntes (streams) de tradições culturais: "A construção cultural que fazem da realidade não surge de uma única fonte e não é monolítica" ${ }^{\text {32. }}$.

Outro aspecto a ser esclarecido refere-se à denominação de Praças. "O próprio termo usado para os soldados alistados, "praças", localizavaos linguisticamente na rua" 34 . A rua assume a condição de ser um espaço relacionado à vadiagem, à ilegitimidade, ao perigo, em contraste com a percepção usual do brasileiro da casa, lugar de ordem, segurança, casamento e de famíliai $27,34,35$.

Nas sessões de grupoterapia predomina a ideia de que o sujeito é o principal responsável pelo seu adoecimento e pela manutenção de sua sobriedade, frisando-se que nunca será curado, levandoos a incorporarem a visão reinante nas salas de AA de que os pacientes são "doentes alcoólicos em recuperação". Os terapeutas geralmente orientam os pacientes a se manterem em um estado de permanente vigilância, desconfiando até das "aparentes" melhoras. A participação dos aspectos sociais, econômicos, laborais e culturais na produção de suas experiências com as diversas substâncias é pouco discutida nas sessões. A expectativa de que o paciente consiga entrar em abstinência como evidência concreta de sua recuperação acaba sendo um aspecto central no cotidiano do CEDEQ, esperando que ele aja e que coloque em prática o programa de recuperação ${ }^{36}$.

Os relatos dos pacientes confirmaram que a questão do uso de drogas na MB é preferencialmente abordada pelo viés administrativo, com a aplicação de punições que é regida pelo $\mathrm{RDM}^{37}$. O item 35 do Título II, Capítulo I, artigo 7o desse regulamento, por exemplo, estabelece como contravenção disciplinar: "apresentar-se em Organização Militar em estado de embriaguez ou embriagar-se e comportar-se de modo inconveniente ou incompatível com a disciplina militar em Organização Militar".

A análise dos relatos obtidos nas observações de campo, grupos terapêuticos e entrevistas, procurou circunscrever como os pacientes significaram os seus processos de adoecimento e cura a partir de seus próprios conteúdos e da incorporação de um ideário oriundo do discurso hegemônico em ação no CEDEQ e nas salas de AA. Esta perspectiva permitiu decifrar e compreender a verdade pela perspectiva dos pacientes do $\mathrm{CEDEQ}^{38}$.

É uma mentalidade que guarda em sua essência a lógica disciplinar que pode ser historicamente traçada, conforme diversos autores já abordaram noutras ocasiões ${ }^{39-43}$. O corpo "adoecido", perscrutado por múltiplos instrumentos diagnósticos que fazem emergir sinais e sintomas corporais, não é, na verdade, propriedade do campo biológico, mas resultado de uma história e de efeitos de poder. Trata-se de uma fabricação cultural da corporalidade, de um corpo que não é universal, mas que é capaz de incorporar cada ato e afeto; e, ao atualizar suas experiências no corpo, faz eclodir um rol de disfunções, um corpo que tem agência, que fala de si e do meio, de suas funções e disfunções ${ }^{44}$. Este processo de construção se alinha com a noção de habitus relacionando-o à capacidade de uma determinada estrutura social ser incorporada pelos agentes (indivíduos) por meio de disposições para sentir, pensar e agir ${ }^{45}$. Corpo atravessado por fluxos de poder, de mandos e desmandos, pelas próprias mazelas e peculiaridades da sociedade e da vida militar, contexto capaz de produzir o habitus alcoólico 7 . "Comportamento alcoó- 
lico" que é postural, gestual, como uma linguagem que vai sendo incorporada no decorrer da carreira naval, amparada por crenças e mitos que associam o álcool à virilidade e à alegria. Com efeito, o controle do corpo é culturalmente e socialmente aprendido ${ }^{46,47}$. E por que não pensar $\mathrm{o}$ mesmo do seu descontrole?

Ao ser percebido e tratado como sujeito que tem uma conduta desviante que deve ser corrigi$\mathrm{da}$, as autoridades navais optam por abordar o uso de drogas através dos instrumentos de controle, fazendo uso esporádico das alternativas assistenciais. De fato, os encaminhamentos são tímidos, geralmente feitos quando o militar já cometeu muitos transtornos a bordo e deu sinais de prejuízos orgânicos mais evidentes, apesar da permanente divulgação do CEDEQ no meio naval e das palestras que a equipe realiza sobre drogadicção. Apesar do número de atendimentos ter reduzido, como exposto na Figura 4, a percepção dos pacientes indica que existe um o grande número de militares afetados: No trabalho, não sei se a Senhora sabe, mas a Marinha tá infestada de usuário de droga, por causa da facilidade e da curiosidade. Antigamente tinha que subir morro. Agora tem o 'disque-droga' (Hélio). Isto revela que a situação do uso de drogas na $\mathrm{MB}$ ainda não foi mapeada, dificultando a aplicação de medidas de proteção nos diferentes níveis.

O CEDEQ parece reproduzir, parcialmente, o discurso institucional. Como ambulatório incumbido do atendimento a dependentes químicos, ele se divide entre duas ordens, a biomédica e a militar. Embora a ênfase recaia nas ações terapêuticas, sua estrutura se ancora no arcabouço militar, e seus profissionais, a seu turno, encontram-se submetidos ao sistema naval. O CEDEQ encon- tra-se envelopado, inserido em um dos capilares do organograma institucional e subordinado à Diretoria de Saúde da Marinha. Apesar de ter nascido para ser um polo de tratamento da dependência química, na prática não é mais do que um ambulatório especializado, deixando de refletir os anseios originais. Este cenário pode espelhar o desinteresse pela questão da drogadicção.

No dia a dia do CEDEQ, profissionais e pacientes tentam gerir situações que são peculiares do cotidiano laboral que atravessam, permanentemente, o tratamento que, de fato, não podem ser vistas como estranhas ao processo, mas intrínsecas a ele. O próprio stress no trabalho e outros fatores laborativos contribuem para a emergência do alcoolismo de muitos pacientes ${ }^{7}$, atestando que a visão proposta sobre a toxicomania parece ter efeito. Hélio expõe: A pessoa que tá muito estressada, se já conhece a droga e tá cansada, acaba procurando!

Um dos efeitos dessa influência se faz presente de forma sutil pela escolha da abordagem terapêutica baseada nos 12 Passos e nas 12 Tradições dos AA e NA que acaba sendo usada como estratégia de convencimento para que os sujeitos incorporem a ideia de que são portadores de uma doença progressiva, incurável e fatal (sobretudo no caso da dependência do álcool).

Em suma, este estudo é relevante não apenas por ser inaugural nas Forças Armadas brasileiras, mas também por ser um tema de saúde pública direcionado à saúde de um trabalhador que está imbuído da missão de defender a pátria. É capital que empresas e organizações dêem atenção às condições laborativas que facilitam o uso de drogas a fim de protegerem seus recursos humanos e materiais.

\section{Colaboradores}

EE Halpern e LMC Leite participaram igualmente de todas as etapas de elaboração do artigo. 


\section{Referências}

1. Luz MT. Natural, racional, social: razão médica e racionalidade científica moderna. Rio de Janeiro: Campus; 1988.

2. Luz MT. $1^{\circ}$ Seminário do projeto racionalidades médicas. Rio de Janeiro: Instituto de Medicina Social (IMS). Universidade Estadual do Rio de Janeiro (UERJ); 1992.

3. Luz MT. Racionalidades médicas e terapêuticas alternativas. Rio de Janeiro: Instituto de Medicina Social (IMS). Universidade Estadual do Rio de Janeiro (UERJ); 1993. (Série Estudos em Saúde Coletiva, 62)

4. Camargo Júnior KR. Paradigmas, ciência e saber médico. Rio de Janeiro: Instituto de Medicina Social (IMS). Universidade Estadual do Rio de Janeiro (UERJ); 1992. (Série Estudos em Saúde Coletiva, 6)

5. Alcoólicos Anônimos. O Grupo de AA: onde tudo começa. São Paulo: JUNAAB - Junta de Serviços Gerais de Alcoólicos Anônimos do Brasil; 1996.

6. Brasil. Lei no 6.880 de 9 de Dezembro de 1980 Dispõe sobre o Estatuto dos Militares. Serviço de Documentação da Marinha 1980; 9 dez.

7. Halpern EE, Ferreira, SMB, Silva Filho, JF. Os efeitos das situações de trabalho na construção do alcoolismo de pacientes militares da Marinha do Brasil. Cad. Psicol. Soc. Trab. 2008; 11(2):273-286.

8. Groleau D, Young A, Kirmayer L. The McGill Illness Narrative Interview (MINI): an interview schedule to elicit meanings and modes of reasoning related to illness experience. Transcultural Psychiatry, McGill University, Montréal, Canada. 2006 ; 43(4):671-691.

9. Yin RK. Estudo de caso: planejamento e métodos. Porto Alegre: Bookman; 2005.

10. Tesch R. Qualitative research: analysis types and software tools. New York: Falmer; 1990.

11. Whitley R, Crawford M. Qualitative Research in Psychiatry. Canadian Journal of Psychiatry 2005; 50(2):108-114.

12. Jellinek EM. The disease concept of alcoholism. New Haven, Connecticut: College and University Press; 1960.

13. Neves DP. Alcoolismo: acusação ou diagnóstico? Cad Saude Publica 2004; 20(1):7-14.

14. Fainzang S. Ethnologie des anciens alcooliques: la liberté ou la mort. Paris: Presses Universitaires de France; 1996.

15. O'Donnell JG. De olho na rua: a cidade de João do Rio. Rio de Janeiro: Jorge Zahar Ed.; 2008.

16. Silva Filho JF, Luce C. O declínio do pai, a mimesis e a toxicomania. In: Cruz MS, Ferreira SMB, organizadores. Álcool e drogas: usos, dependência e tratamentos. Rio de Janeiro: Edições IPUB/CUCA; 2001. p. 63-76.
17. Velho G. A dimensão cultural e política dos mundos das drogas. In: Zaluar AG, organizadora. Drogas e cidadania: repressão ou redução de risco. São Paulo: Brasiliense; 1994. p. 23-29.

18. Campos EA. As representações sobre o alcoolismo em uma associação de ex-bebedores: os Alcoólicos Anônimos. Cad Saude Publica 2004; 20(5):1379-1387.

19. Campos EA. O alcoolismo é uma doença contagiosa? Representações sobre o contágio e a doença de ex-bebedores. Cien Saude Colet 2005; 10(Supl.):267278.

20. Mol A. The body multiple: ontology in medical practice. Durham, North Carolina: Duke University Press; 2002.

21. Wikipedia. Marinha do Brasil. [pagina da Internet]. [acessado 2010 abr 29]. Disponível em: http:// pt.wikipedia.org/wiki/Marinha_do_Brasil

22. Castro C. O espírito militar: um antropólogo na caserna. Rio de Janeiro: Zahar Ed.; 2004.

23. Coelho EC. Em busca de identidade: o Exército e a política na sociedade brasileira. Rio de Janeiro: Forense Universitária; 1976.

24. Duarte LFD, Gomes EC. Três famílias: identidades e trajetórias transgeracionais nas classes populares. Rio de Janeiro: Editora da FGV; 2008.

25. Weber M. A "objetividade" do conhecimento nas ciências sociais. In: Cohn G, organizador. Max Weber: Sociologia. Rio de Janeiro: Ática; 2003. p. 79-127.

26. Bourdieu P. A produção da crença: contribuição para uma economia dos bens simbólicos. São Paulo: Zouk; 2005.

27. Da Matta R. A casa e a rua: espaço, cidadania, mulher, e morte no Brasil. Rio de Janeiro: Guanabara; 1987.

28. Velho G. Observando o familiar. In: Nunes EO, organizador. A aventura sociológica. Rio de Janeiro, Zahar Editores; 1978. p. 36-46.

29. Velho G. Nobres \& anjos: um estudo de tóxicos e hierarquia. Rio de Janeiro: Editora Fundação Getúlio Vargas; 1998.

30. Berreman G. Por detrás de muitas máscaras. In: Zaluar AG, organizadora. Desvendando máscaras sociais. Rio de Janeiro: Livraria Francisco Alves Ed. S.A.; 1980. p. 123-174.

31. Garcia AM. "E o verbo (re)fez o homem": Estudo do processo de conversão do alcoólico ativo em alcoólico passivo. Niterói: Intertexto; 2004.

32. Barth F. A análise da cultura nas sociedades complexas. In: Lask T, organizador. O guru, o iniciador e outras variações antropológicas. Rio de Janeiro: Contra Capa Livraria Ltda.; 2000. 
33. Hughes EC. Introduction: the place of field work in social science. In: Junker BH, editor. Field work: an introduction to social sciences. Chicago: University of Chicago Press; 1960.

34. Beattie PM. Ser homem pobre, livre e honrado: a sodomia e os praças nas Forças Armadas brasileiras (1860-1930). In: Castro C, Izecksohn V, Kraay $\mathrm{H}$, organizadores. Nova história militar brasileira. Rio de Janeiro: Editora FGV; 2004. p. 269-299.

35. Freyre G. Sobrados e mucambos: decadência do patriarcado rural e desenvolvimento do urbano. Rio de Janeiro: José Olympio Editora; 1936/1977.

36. Mäkelä K. Alcoholics Anonymous: as mutual-help movement: a study in eight societies. Wisconsin: University of Wisconsin Press; 1996.

37. Brasil. Decreto no 88.545 de 26 de julho de 1983. Aprova o Regulamento Disciplinar para a Marinha e dá outras providências. Serviço de Documentação da Marinha 1983; 26 jul.

38. Spradley J. The ethnographic interview. Fort Worth, TX: Harcourt Brace; 1979.

39. Foucault M. Vigiar e punir: nascimento da prisão. 34a ed. Petrópolis: Vozes; 1975/2007.

40. Luz MT. Medicina e ordem política brasileira: políticas e instituições de saúde (1850-1930). Rio de Janeiro: Edições Graal; 1982.

41. Rago LM. Do cabaré ao lar: a utopia da cidade disciplinar: Brasil 1890-1930. 2a ed. Rio de Janeiro: Paz e Terra; 1985.

42. Jardim SR. O trabalho e a construção do sujeito. In: Silva Filho JF, Jardim S, organizadores. A danação do trabalho: relações de trabalho e o sofrimento. Rio de Janeiro: Te Corá Editora; 1997. p. 79-88.

43. Greenhalgh JFL. Presigangas e calabouços ou prisões da Marinha no Século XIX. Rio de Janeiro: Serviço de Documentação da Marinha; 1998.

44. Csordas TJ. Embodiment as a paradigm for anthropology. Ethos 1990; 18(1):5-47.

45. Bourdieu P. O poder simbólico. Rio de Janeiro: Bertrand Brasil; 2007.

46. Mauss M. As técnicas corporais. In: Mauss M, organizador. Sociologia e antropologia, com uma introdução à obra de Marcel Mauss, de Claude Lévi-Strauss. São Paulo: EPU; 1935/1974. p. 211-233.

47. Douglas M. Natural symbols: explorations in cosmology. London: Barrie \& Rockliff; 1970.

Apresentado em 21/10/2010

Aprovado em 13/12/2010

Versão final apresentada em 21/01/2011 